\title{
Students’ Abstraction Process through Compression to Thinkable Concepts: Focusing on Using "How to" in Learning Units of Lesson Sequences to Provide a Tool in Conducting Students' Concepts
}

\author{
Nisara Suthisung ${ }^{1}$, Maitree Inprasitha ${ }^{2}$, Kiat Sangaroon ${ }^{3}$ \\ ${ }^{1}$ Doctoral Program in Mathematics Education, Faculty of Education, Khon Kaen University, \\ Khon Kaen, Thailand \\ ${ }^{2}$ Center for Research in Mathematics Education, Faculty of Education, Khon Kaen University, Khon Kaen, Thailand \\ ${ }^{3}$ Centre of Excellence in Mathematics, CHE, Bangkok, Thailand \\ Email: muinisara@hotmail.com
}

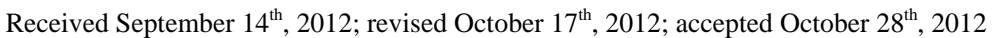

\begin{abstract}
The purpose of this study is to analyze "how to" in the students' abstraction process through compression to thinkable concept under classroom using Lesson Study and Open Approach. Data for this study were collected by using a teaching experiment, with the four of first graders as targeted. The research results revealed that in the students' abstraction process, they compressed computable symbols and conducted 10 as "how to" in their thinking and thinkable concept at the same time. It is shift steadily from performing sequence of compression in students' thinking from actions being linked together in increasingly sophisticated ways.
\end{abstract}

Keywords: Lesson Study; Open Approach; Precept; Compression to Thinkable Concept; How to; Learning Unit

\section{Introduction}

The objective of Learning and Teaching Mathematics is to develop students' concept in content. Teachers and researchers try to search for instruments to comprehend student's existing concepts (Gray \& Tall, 2007). In Thailand, instruction in the classroom using an Open Approach as an innovative teaching approach that cooperates with a Lesson Study is an effective way to develop mathematical activity using open-ended problems for promoting the use of tools in students' problem solving and in developing their concepts (Inprasitha, Pattanajak, \& Thasain, 2007). Therefore, to depend on the area of teaching implementation in a classroom for studying the abstraction process with natural occurrences is a major guideline in considering and finding answers to understand the concept formation of students.

Skemp (1987) explained the abstraction process as an important instrument in developing concepts and considered the fundamental human activities to be perception, action and reflection. Tall (2004) considered students' mathematical thinking growth based on perception and action through compression to thinkable concept to develop their concept. Gray and Tall (2007) viewed that the abstraction process through compression to thinkable concepts is the key to developing increasingly powerful thinking. This point of view focused that instructional must be framed with an awareness of students' abstraction process to produce thinkable concept. Tall (2007a) noted that thinkable concepts must be integrated in the curriculum. However, there was no empirical evidence. Therefore, the researchers and educators should study and make it clear for teachers, students and parents.

Gray and Tall (1994) explained the abstraction process of compression operation arithmetic using procedures in problem solving to the same effect. Tall (2004) suggested that the changing process from procedures to thinkable concept cannot be seen easily. Tall and Isoda (2007) described in classroom using Lesson Study caused to the student's abstraction process for concept formation from considering compression to thinkable concept through 4 steps of procedures in problem solving to effect based on Tall (2006) five steps of thinkable concept.

Lesson Study and the Open Approach have been integrated into Thai classrooms. It was a unique teaching for developing students thinking process, continuing, analyzing teaching and controlling classrooms. Inprasitha et al., (2007) adopt the concept of Lesson Study from Japan. It is focused on changing to develop the learners' progress in real class with team collaboration, observers and reflection, creating problem situation, designing learning materials and steps of teaching. According to Inprasitha (2010), the Open Approach is a teaching approach to solve problems and understand the learning content of solving problems, including four steps as follows: posing open-ended problems, students' self-learning, whole class discussions and summary through connection.

Survey the opinions of teachers in four schools, participating in the project under Center for Research in Mathematics Education, Faculty of Education, Khon Kaen University for four years using the Open Approach and a Lesson Study has found that teachers are concerned and eager to help their students to build thinkable concepts. The teachers used daily life problems that the students had already known as well as designed touch- 
able learning tools and designed problem situation focused on using tools in students' problem solving, and the teachers produced "how to" in learning unit of lessons sequence. So the students could solve mathematical problems, wrote symbolic sentences easily.

Tall (2007b) argued that Lesson Study provides an area for the students' compression to thinkable concepts. Moreover, Tall (2008) suggested that Lesson Study is to be the major idea to support students have "how to" in solving problem for compression to thinkable concept. The purpose using Lesson Study in Thai classroom is producing "how to" as a tool in thinking to build students' concept, which is designed in learning unit of lessons sequence to support using as a tool in students' solving problem in step students' self learning of Open Approach (Inprasitha, 2010).

From the above rationale, the researchers was interested in studying the students' abstraction processes through compression to thinkable concepts focusing on empirical evidence in context using Lesson Study and Open Approach, and using their "how to" in problem solving and how can it be conducted to thinkable concepts.

\section{Objective}

To analyze students' abstraction process through compression to thinkable concepts focused on using "how to" in units of lessons to provide a tool in conducting students' concepts.

\section{Context of Study}

Thinkable concepts are the teaching and learning goals. In achieving that, teachers should provide appropriate learning experiences for students. Using Lesson Study with Open Approach from open-ended problem and interacting with learning materials can support and develop students' thinkable concept. Students are able to think from their daily lives problems, interact with learning materials, use symbolic for calculation. Especially, considering "how to" is a tool in the students' problem solving and is playing a key role to product thinkable concept in their abstraction process through compression under the views as following:

\section{Lesson Study}

Lesson Study is an innovative tool for building, analyzing classrooms and developing students' mathematical thinking. Inprasitha et al., (2007) adapted the concept of Lesson Study from Japan to be used in Thai classes. It consists of three steps in planning, observing and reflecting as follows:

Teachers, observers, internship mathematics student teachers, research team wrote teaching plans in units and periods, learning activities, objectives and open-ended problems using a Japanese textbook (Gakkoh Tosho, Study with Your Friends mathematics for Elementary School 1st grade). It was team collaboration consisting of designing learning materials, steps of teaching, predicting students' ways of thinking. Designed learning materials for helping students to think, act and processed from well being plans.

The next step was to bring the team teaching plan to use with the Open Approach (it will be mentioned later.) The team observed a teacher, the students' way of thinking, how they solved problems, their interactions with learning materials, and their expected and unexpected concepts.

At the reflection step, the team reflected on many aspects, the students' ways of thinking that happened in class.

By studying the Lesson Study as it is taught by the team, we can observe the students' ways of thinking through compression to thinkable concepts by using a Lesson Study and the Open Approach from the above theories.

1) Collaboratively for designing lesson plan, using Open Approach from problem situation in students' real life, create designed materials to support students' concepts. Focused on lesson's goal, learn how to learn, timing for each period, designing 4 steps of teaching (Figure 1).

2) Collaboratively observe in class, bring the team teaching plan to use with Open Approach (It will be mentioned later). The team observed a teacher, the students' way of thinking, how they solved problems, their reaction to designed materials for using symbolic calculation to solve problem situation (Figure 1).

3) Collaboratively reflect, discussing problems and obstacles in using lesson plans as well as considering the position of using designed materials, students' way of solving problem, students' new ways of thinking, and the successful of using lesson plans (Figure 1).

In addition, using the Open Approach is an important teaching approach that motivates the students to think, so it was used in this research.

\section{Open Approach}

Nohda (1998) believed that the Open Approach could be used for supporting various kinds of student activities and mathematical problem-solving. The Open Approach is a teaching approach that helps students to reflect on their own thinking, to solve various kinds of problems, and it is essential for all students to do their mathematical tasks to the best of their abilities. Nohda (2000) mentioned that Open Approach can adjust several ways of students thinking or students' mathematics thinking and the progress of teaching approach should be integrated. Open Approach is expected to be a tool for changing classroom, helping students to learn from their abilities. Open Approach is aimed at the students can think on their own. In Thailand, Lesson Study has been used with the Open Approach as a teaching approach in four steps according to Inprasitha (2010). It is started from posing open-ended problem situations, student's self-learning, whole class discussion and comparison, and summary through connection. Students learn and understand the contents by solving problems.

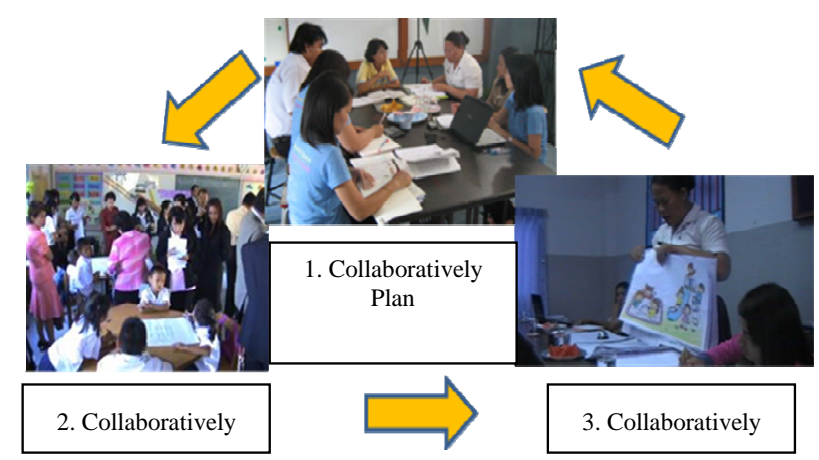

Figure 1.

Cycle of Lesson Study including 3 phases. 
1) Posing Open-ended problem: A teacher posed to encourage students to solve problem (Figure 2 (a)).

2) Students' self-learning: They made goal-directed thinking, attempted to solve problem with different methods (Figure 2(b)).

3) Whole classroom discussion and comparison: The students presented their ideas in front of the class. They realized and checked way of thinking in order to systematically explain their ideas (Figure 2(c)).

This research focused on the teaching steps: students' selflearning. The students used learning tools and different ways to solve problems that led them to build thinkable concepts.

From the above framework, the related theories, the procedures of "how to" in students' abstraction process through compression to thinkable concept are as follows.

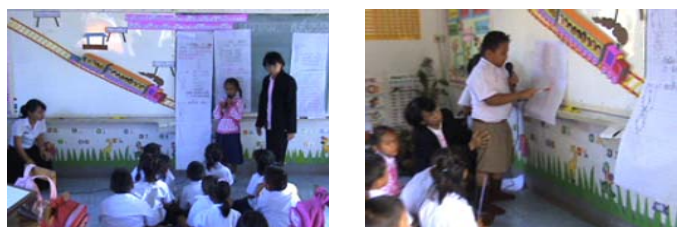

Teacher: A teacher posed a problem situation that was close to students real world problem. Student: Students perceived problem situation through seeing and hearing. They paid attention and were eager to solve that problem. The problem situation seemed to be their problem.

(a)
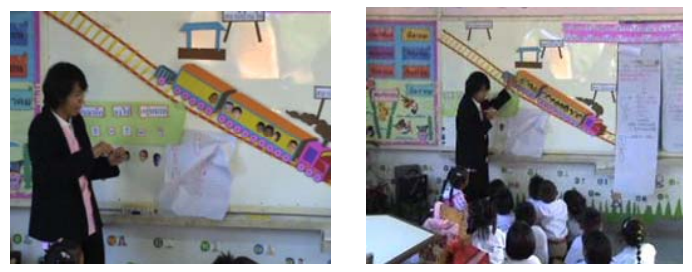

Teacher: After posing the problem, the students thought and did self-learning. Student: The students solve the problem by themselves and used symbolic calculations. They created various way and goal-directed thinking, and tried to write formal mathematical symbols and formal language into mathematical world before coming to mathematical concepts.

(b)
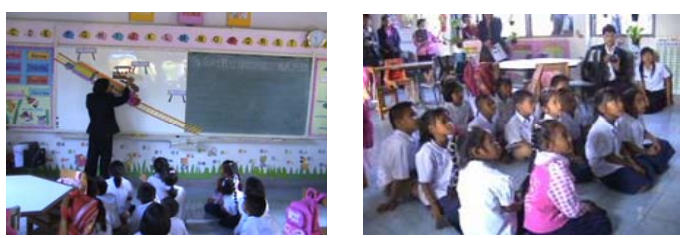

(c)
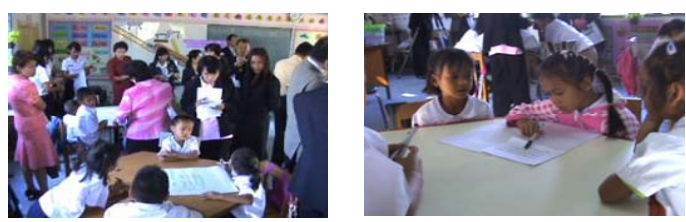

Teacher: The teacher connected the students' idea by presenting main ideas to summarize the main points for understanding. Student: The students realized the different ways of calculation. The teacher summarized through connection to the main concept for giving students. They have opportunity to revise concept.

(d)

Figure 2.

Four steps of Open Approach.

\section{"How to"}

Inprasitha (2010) explained that the Lesson Study teams planned the study lesson with an emphasis on "how to" which was a key influence for engaging students in the self learning phase (i.e. students' problem solving). Isoda (2010) viewed that teachers plan the lesson and teach that children enable to learn the value of mathematics and "how to" develop mathematics as well as mathematical idea and skills.

Thus, designing learning unit in such a way the lesson study team has to be concerned with what are important "how to" within a unit and between units.

The purpose of using a Lesson Study In Thai classroom of producing "how to" as a tool in thinking to build students' concept, which is designed in learning unit of lessons sequence to be used as a tool in students' problem solving. Moreover, Tall (2008) suggested that the Lesson Study be the major idea to support children having "how to" in solving problems for compression to thinkable concept. Therefore, it is interesting for studying how it can be conducted to thinkable concept.

\section{The Designing Learning Unit}

Inprasitha (2010) suggested that in the Japanese textbook of the 1st grade mathematics textbook, the sequence of learning units be as follows: number up to 10, decomposing, numerical order, addition (1), subtraction (1), number larger than 10, addition (2), subtraction (2) then add or subtract (Gakkotosho Co., Ltd., 2005). The reasons why the Japanese textbook designs the sequence of learning units as such as:

- Most of the first grade students have experience in "order number" outside of the school. They can count by one before entering the school. However, it is difficult for them to conceptualize the number 5 as the combination of each number.

- Before making addition, they must see the number 9 as $(1,8),(2,7),(3,6),(4,5)$.

- They must see the value of the "base ten", that is, they see the number 8 , they should combine with 2 to make it becomes 10 , and

- They must use it as a tool in their problem solving and constructing concept.

The above mentioned "how to" appeared in the decomposing unit of the Japanese textbook and prepared the tool that the students were to use when they learn the addition, subtraction and add or subtract unit. From this point of view, just designing the learning units in the Lesson Study process are not a guarantee for students' self-learning, and this design should be concerned with the teaching approach. The following example illustrates this idea:

1) In the decomposing unit, the students learn the structure of numbers 5, 6, 7, 8, 9 and 10, "number patterns among the combination of those numbers", and the value of base 10 . Then, they learn how to add numbers where the result is not more than 10 (Figure 3).

2) In the addition (1), subtraction (2) and add or subtract units, they use decomposing numbers and "base ten" as tools in problem solving. Then, they learn how to add or subtract where the result is more than 10 (Figures 4 and 5).

The following sub-unit extended the idea of addition and subtraction in order that students uses those "how to" tools to make addition and subtraction with a result of not more than 20 . The empirical data below were collected in the 2010 academic 


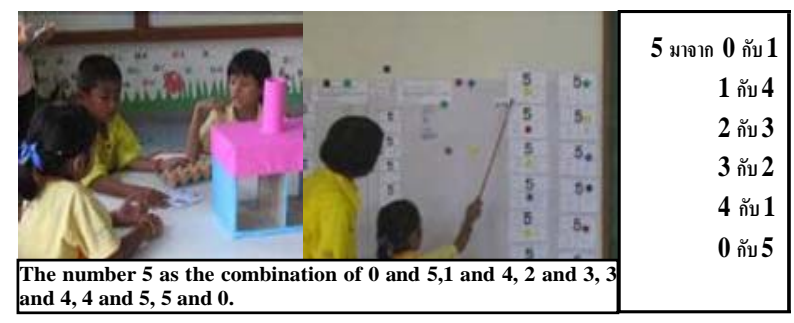

Figure 3.

Decomposing unit.

\section{Example in addition unit (2)}

Problem situation 1: There are 9 children on the sand box and 4 children on the seesaw. "How many children are there in all?”

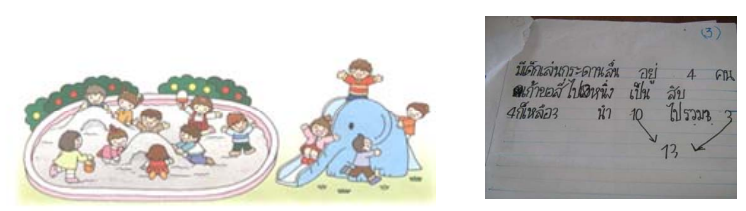

The students used diagram as thinking tools. They decomposed 4 to 1 , 3 and composed 9 with 1 to 10 and added them to 13 .

Problem situation 2: There were 9 eggs yesterday and there are 7 eggs today. From a question: "How many eggs are there?"
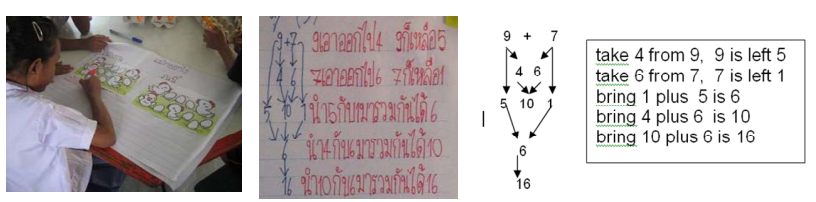

Figure 4.

Addition unit.

\section{Example in subtraction unit (2)}

Problem situation 3: Which is more, chicks or roosters?

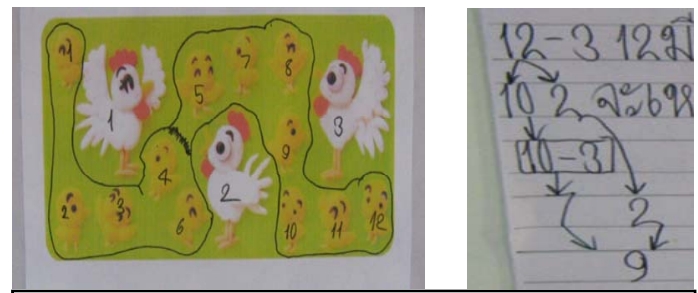

The students' thinking used a diagram for decomposing, composing and recomposing based on base ten.

\section{Figure 5.}

Subtraction unit.

year from first grade students at Kook-Kham Pittayasan School in the Northeastern part of Thailand. This school has been implemented Lesson Study and Open Approach since 2006.

Thus, designing learning unit in such a way the lesson study team has to be concerned with what are important "how to" within a unit and between units.

The purpose of using a Lesson Study In Thai classroom of producing "how to" as a tool in thinking to build students' concept, which is designed in learning unit of lessons sequence to be used as a tool in students' problem solving. Moreover, Tall (2008) suggested that the Lesson Study be the major idea to support children having "how to" in solving problems for compression to thinkable concept. Therefore, it is interesting for studying how it can be conducted to thinkable concept.

\section{Conceptual Framework for Analyzing Compression to Thinkable Concept}

\section{Precept}

Gray and Tall coined term the "precept" in 1994. It has dual characteristics of process and object from the same symbol to same effect through compression to thinkable concept. Using process to precept is natural process compression sequencing from process to concept formation. Precept is the changing process from procedures to thinkable concept in accordance with evolutionary development, according to Tall et al., 2000 (Table 1).

Those concepts are in harmony with the SOLO Model (Bigg \& Collis, 1982), which mentions Unistructural, Multistructural, Relational and Extended Abstract. Davis (1984) divided to procedure and integrated to process and entity. Sfard (1991) comprised of interiorization, condensation and reification. APOS of Dubinsky (1991) comprised of action, process, and object and expanded to schema according to Pegg and Tall (2005: p. 472) as shown in the Table 2.

Table 1.

Development of precept.

\begin{tabular}{|c|c|c|c|}
\hline & Process & $\ldots$ & Concept \\
\hline $\begin{array}{l}\text { Piaget } \\
\text { (1950s) }\end{array}$ & $\begin{array}{c}\text { Action(s), } \\
\text { Operation(s)... }\end{array}$ & $\cdots$ & $\begin{array}{c}\text { Thematized } \\
\text { object of } \\
\text { thought }\end{array}$ \\
\hline $\begin{array}{l}\text { Dienes } \\
(1960 \mathrm{~s})\end{array}$ & Predicate... & $\cdots$ & Subject \\
\hline Davis (1980s) & $\begin{array}{l}\text { Visually moderated } \\
\text { Sequence... }\end{array}$ & $\begin{array}{l}\text { Integrated sequence... } \\
\text { Seen as a whole, and } \\
\text { can be broken into } \\
\text { sub-sequence }\end{array}$ & $\begin{array}{l}\text { a thing, an } \\
\text { entity, a noun }\end{array}$ \\
\hline $\begin{array}{l}\text { Greeno } \\
\text { (1980s) }\end{array}$ & Procedure... & $\begin{array}{c}\text { Input to another pro- } \\
\text { cedure... }\end{array}$ & $\begin{array}{c}\text { Conceptual } \\
\text { entity }\end{array}$ \\
\hline $\begin{array}{l}\text { Dubinsky } \\
\text { (1980s) }\end{array}$ & $\begin{array}{c}\text { Action... Each step } \\
\text { triggers the next }\end{array}$ & $\begin{array}{l}\text { Interiorized process... } \\
\text { With conscious control }\end{array}$ & $\begin{array}{c}\text { Encapsulated } \\
\text { object }\end{array}$ \\
\hline Sfard (1980s) & $\begin{array}{c}\text { Interiorized } \\
\text { process... Process } \\
\text { performed }\end{array}$ & $\begin{array}{l}\text { Condensed process... } \\
\text { Self-contained }\end{array}$ & Reified object \\
\hline $\begin{array}{c}\text { Bigg and } \\
\text { Collis (1980s) }\end{array}$ & $\begin{array}{l}\text { Unistructural } a \\
\text { single procedure }\end{array}$ & Relational & $\begin{array}{c}\text { Extended } \\
\text { abstract }\end{array}$ \\
\hline $\begin{array}{l}\text { Gray \& Tall } \\
\text { (1990s) }\end{array}$ & $\begin{array}{c}\text { Procedure... } \\
\text { Specific algorithm }\end{array}$ & $\begin{array}{c}\text { Process...Conceived as } \\
\text { a whole, irrespective of } \\
\text { algorithm }\end{array}$ & $\begin{array}{l}\text { Procept, symbol } \\
\text { evoking } \\
\text { process or } \\
\text { concept }\end{array}$ \\
\hline
\end{tabular}

Table 2.

Step of precept.

\begin{tabular}{|c|c|c|c|c|}
\hline SOLO Model & Davis & Sfard & $\begin{array}{l}\text { APOS of } \\
\text { Dubinsky }\end{array}$ & $\begin{array}{c}\text { Gray \& Tall } \\
\text { [Base Objects] }\end{array}$ \\
\hline $\begin{array}{l}\text { Unistructural } \\
\text { Multistructural }\end{array}$ & $\begin{array}{l}\text { Procedure } \\
\text { (VMS) }\end{array}$ & Interiorization & Action & Procedure \\
\hline Relational & $\begin{array}{c}\text { Integrated } \\
\text { Process }\end{array}$ & Condensation & Process & Process \\
\hline \multirow[t]{2}{*}{$\begin{array}{l}\text { Unistructural } \\
\text { (in a new cycle) }\end{array}$} & Entity & Refication & Object & Procept \\
\hline & & & Schema & \\
\hline
\end{tabular}


Moreover, Tall (2004) believed that the changing process from procedures to thinkable concept cannot be seen easily. Therefore, we described the concept based on empirical evidence according to the above theories in the students' abstraction process through compression to thinkable concept. These various underlying frameworks have a general development of increasing flexibility and compression, which is introduced in an overall problem-solving way in Lesson Study.

\section{Compression to Thinkable Concept}

Tall and Isoda (2007) suggested that a classroom developed through Lesson Study does not limit students to think, it helps the students to think and act differently in solving problem to same effect through four steps of compression to thinkable concept as follows:

1) Aprocedure; 2) Multi-procedure; 3) An overall process: to recognize the different ways that related in each steps to same effect; 4) A thinkable concept or procept according to Gray and Tall (1994): it has dual characteristics of a process in calculation to the same effect through compression to thinkable concept.

The above concept based on Tall (2006), developed the five continuous steps through compression: 1) pre-procedure; 2) a procedure; 3) procedures; 4) multi-procedure and 5) thinkable concept.

This study considered increasingly sophisticated ways of mathematical problem-solving to the same effect, the students' procedures using "how to" in the abstraction process through compression to thinkable concept. This study presented the students' abstraction process in specific problem situations to thinkable concept in blending the embodiment (learning materials) with the written symbol.

\section{Methodology}

This research study was conducted by Teaching Experiment (Leslie \& Patrick, 2000), to analyze students' abstraction process focused on several ways and "how to" they use to solve problem and chose important concept to build thinkable concept. The researchers treated Open Approach as a sequence of teaching in class to study students' mathematical thinking with target group using video, photographs, protocol, tape recording, field notes, interviewing teachers, teacher trainees and collaboratively observed in class to analyze the data in framework (it will be mentioned later.) The researchers embedded to study learning and teaching culture for 3 years, target group was one of four schools in the project under Center for Research in Mathematics Education, Faculty of Education, Khon Kaen University for 5 years. It was a small and typical school with only one class in each grade. The first grade students were used Lesson Study and Open Approach in three steps collecting data as following:

Teaching plans were divided into two periods: before semester and after semester. Before semester, teachers, observers, internship mathematics student teachers, and the research team wrote the teaching plan in units and periods, learning activities, objectives and open-ended problems using Japanese textbook. It was a team collaboration of four schools. During the semester, there were teaching plans on Tuesdays for this school, using students' concept in class students' prior knowledge, experiences as well as expecting students' ideas in doing mathemati- cal activities, open-ended problems. There was instruction for students to reveal thinking concept during doing mathematical activity and to create teaching plans and materials together. In class teaching focused on four steps of teaching procedures: posing open-ended problem situations, student's self-learning, whole class discussion and summary through connection. The data was collected by tape recording and analyzed with the other steps.

At the teaching step, the teachers taught in class after team planning, focused on the importance of thinking time, and the students presented their work in front of the class. Teachers walked around to see the students' concept, to arouse them showing their way of thinking, and help them in class presentation by using authentic teaching materials. Observer team (teachers, internship mathematics student teachers, school coordinators, and researchers) participated at this step in class by observing students' ideas and oral presentation in front of the classroom. Observer teachers, teachers, internship mathematics student teachers, research team, school administrators participated at this step. They observed students' tasks: oral and action to build thinkable concept. Used Open Approach to collect and analyze the data.

Observer teachers, teachers, internship mathematics student teachers, the research team and school administrators participated at the reflecting step in each classroom. They observed students' concept and their tasks. The data was collected by tape and video recording, and these were analyzed.

Collected data from the teaching experiment in class to see the procedures of 4 targeted students' abstraction process through compression to thinkable concept with conceptual analysis, using video recordings, field notes, pictures, interviewing witnesses in instruction background assembles (teachers, observer teachers and internship mathematics student teachers) and analyzing students' tasks with triangulation.

The data was from class observing, protocol, interviewing and students' tasks. Students' concepts were analyzed using the problem situation "get on the train" $(9+5-7=7)$ from team collaboration to build and analyze classroom teaching from planning lessons focusing on an open-ended problem situation as mention above. The students' oral and active presentations were observed and analyzed. Empirical evidence in teaching scenes was analyzed to understand how the students formulated the concept of "addition and subtraction". The purpose of analyzing teaching scenes was to study "how to" as a tool in the students' abstraction process through compression to thinkable concept under classroom using Lesson Study and Open Approach. The data was analyzed based on the framework that proposed by Tall and Isoda (2007). The analyzing was divided into three parts: 1) Analyzing students' way of thinking in solving problem

2) Analyzing students' abstraction process through compression to thinkable concept in symbolic calculation and

3) Analyzing "how to" in the students' abstraction process through compression to thinkable concept under classroom using Lesson Study and Open Approach.

\section{Analysis and Results}

Example analysis grade 1 activity "get on the train" from add or subtract unit, a teacher presented problem situation and stuck the material designed instruction on the blackboard for the students. They read, “There are 9 students at Khon Kaen station, 5 
students get on the train at Ban Pai and 7 students get off at Muang Phol station, so how many students are there on the train?” Learning materials were some paper, a picture of running train and a picture of each student on the train. Students prior knowledge was construct 10 from decomposing and composing, using diagram as thinking tool. This situation focused on writing symbols addition and subtraction using diagram and base 10 under the theory of Tall and Isoda (2007).

The problem situation "get on the train" was closed to students' daily lives and used a picture as a teaching tool to motivate students to solve problem on open-ended problem situation. To find the answer and use the Open Approach as teaching tool for supporting and promoting students' abstraction process to thinkable concept.
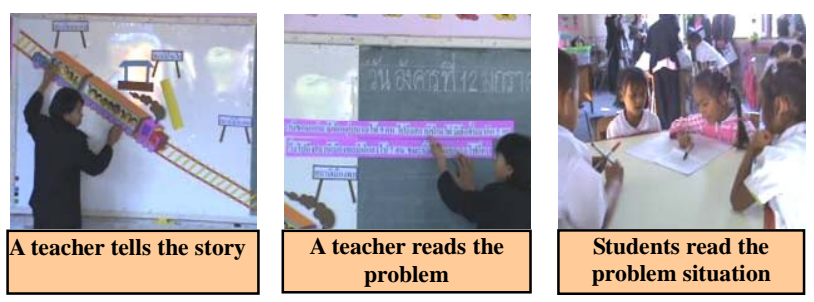

Students used base 10 and a diagram as a thinking tool to the same result. Students decomposed the first and second number and composed numbers to build 10 and decomposed 10 with the third number. Students understood the meaning of symbol “+” for addition and “-” for subtraction $(9+5-7=7)$. They checked the result by picking the learning materials (as in Figure 6).

\section{1) To analyze the students' thinking process}

The focus switches to the number of children on the train, which was found by counting. Looking at different ways of performing the operation, as $9+5$ then take away 7 or $9+1$

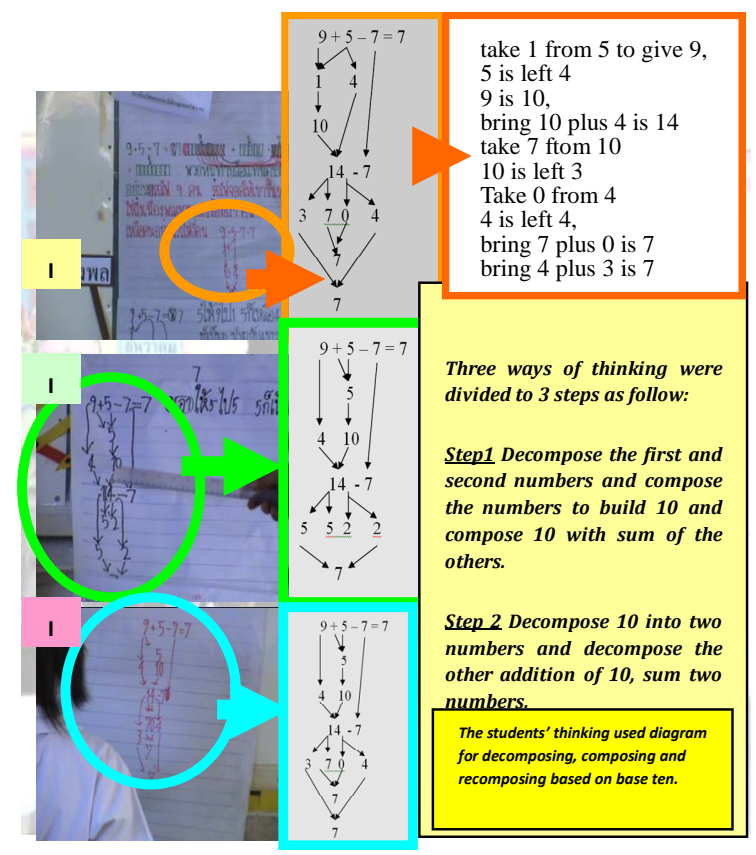

Figure 6.

The students' thinking using diagram for decomposing, composing and recomposing based on base ten. making ten, plus 4 and taking away 7, and so on. This is the operational world of mathematics in which different operations can have the same effect. It is the effect, the total number that matters.

This is performed even more efficiently by simply focusing on numbers and their operations and, in particular, the flexibility of those operations. It means not just knowing lots of different ways of doing something, it means simplifying the problem by choosing an efficient and meaningful way of getting the answer, to make the arithmetic simpler.

Students used base 10 and diagram as thinking tools for the same result. Students' ways of thinking were to decompose the first and second numbers and compose numbers to build 10 and subtract from the third number to find answer. Students understood the symbol + for addition, - for subtraction from symbolic sentence $(9+5-7=7)$. At last, they checked the answer by picking designed materials. The answer was seven as from the symbolic sentence, and the students' way of thinking was divided into three steps to the same effect: building 10 with other numbers decompose 10 to subtract from the other number and compose number from step two.

2) To analyze compression to thinkable concept in the students' abstraction process from symbolic sentence

Considering the procedure to thinkable concept of the students three methods in solving problem based on Tall and Isoda (2007), especially in final step the students revised and checked way of thinking, they recognized concept formation and this concept was built to utilize later for extending mathematical structure (Suthisung, 2011a, 2011b). These can analyze in area the students' abstraction process. Considering students' tools in steps 3, 4 and 5 from procedure to thinkable concept, the students recognized concept formation and this concept was built to be utilized later.

Moreover, students used learning designed materials to check the result from the problem situation: there were nine students on the train and then five students got on, there were 14 students on the train and after that seven students got off, so there were seven students on the train. Students used formal mathematics symbols and formal written language.

Action of abstraction process focusing on compression to thinkable concept: in what level and how it happens (as in Table 3$)$.

Students used learning designed materials to support and promote their action in problem solving. They used multi-procedures to solve problems to the same effect. They used base 10 and a diagram as learning tools for calculation in addition and subtraction to thinkable concept as follows:

- Students used base 10 from diagram to decomposing, composing and recomposing in accordance with Gray and Tall (1994) the different symbol and process but same effect.

- Students used the form as in No. 1 to get the result. They decomposed and recomposed to get 10 and subtracted from 10.

- The students used different ways to get the same effect. They checked the result and chose the most efficient way to solve the problem.

- Students got the result from multi-procedures. They used 10 by decomposing, composing and recomposing as flexible concepts. Howat (2005) described 10 as a thinkable concept for providing place value.

- Students could create or construct new knowledge from solving the mathematics problems. They used previous 
Table 3.

Using "how to" in abstraction process.

\begin{tabular}{l} 
The step of compression to think- \\
able concept \\
\hline $\mathbf{5}$ revise thinkable concept: Using \\
base ten to bring construct new \\
concept (The effect is extended, the \\
precise effect)
\end{tabular}

(4) a thinkable concept: $9+5-7=$ 7, 10 as thinkable concept, using decomposing, composing and recomposing (The effect is considered as a concept in itself)

3process of calculation from procedures to same effect: $9+1+4$ $7,3+7+0+4-7,5+5+4-7,5$ $+5+2+2-7$ (The realization that the different procedures may involve different sequence of steps, but they all achieve "the same effect)

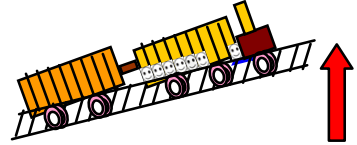

2 multi- procedure: (Several different procedures, to choose the most efficient)

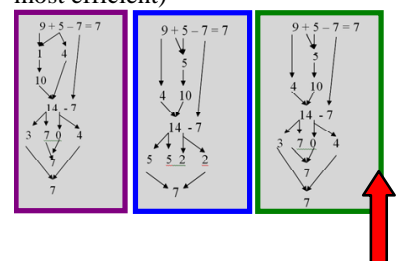

(1) procedure: (A single step-by-step procedure to carry out the operation)

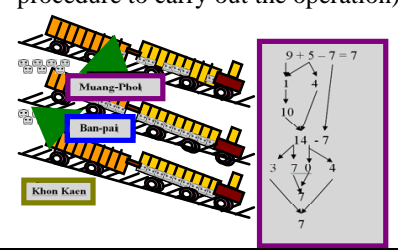

Student (I.67): Take 1 from 5 to give 9,5 is left 4 ,

9 is 10. Bring 10 plus 4 equals to

14. Take 7 from 10,10 is left 3 .

Take 0 from 4,4 is left 4 , then bring 7 plus 0 equals to 7,3 plus 4 equals to 7 .

knowledge to think and find answers in new situations.

Students used 10 to add and subtract. They used decompose, compose and recompose. Gray and Tall (1994) described action compression procedures of idea onto thinkable concept. Tall \& Isoda (2007) said that multi-procedures to solve problems and thinkable concept.

Analysis of "action" in the students' abstraction process through compression to thinkable concept as in Figure 7.

3) To analyze "how to" in the students' abstraction process through compression to thinkable concept under classroom using Lesson Study and Open Approach
Focusing on the number of children on the train at any point and calculating the changing number by adding and subtracting the numbers getting on and off. This is performed even more efficiently by simply focusing on numbers and their operations and, in particular, the flexibility of those operations. It means not just knowing lots of different ways of doing something, it means simplifying the problem by choosing an efficient and meaningful way of getting the answer, to make the arithmetic simpler.

In the study, students used base 10 in addition and subtracttion to same effect. They decompose, compose and recompose again according to Gray and Tall (1994) in "action”, the students' way of thinking through compression to thinkable concept using learning tools in 5 steps as mention before. In the fifth step, the students recognized the concept from solving problem to construct new knowledge in new situations.

It is shifting steadily from performing sequence of compression in students' thinking from actions being linked together increasingly sophisticated ways: accumulation students' way thinking in 1 - 3 step to refine important ideas in step 4 and it is realized to extend useable mathematical structure in step 5 also.

It happened clearly by compression of knowledge from stepby-step procedure, to the possible choice of several different procedures, to seen the overall effect as a general process that can be carried at in various ways, to compressing it as a thinkable concept.

In terms of this Figure 8, for "process", it can be said that procedures such as $9+5-7,10+4-7,14-7$ all have the same effect'. It is interesting that this lesson is about developing the way that the children are encouraged to think flexibly from the start. Thus the sequence procedure-multi procedureprocess-procept occur in continuous steps, indeed, the lesson focuses early on flexibility of arithmetic, so the idea of "process" builds at the same time as the children play with multiprocedures, while implicitly focusing on the flexibility required for precept. This encouragement to think more flexibly leads more naturally to more sophisticated thinking.

In addition, for the students' abstraction process in "action", the students used learning tools to support their thinking. They bridged real world problem to mathematics problem in the step of whole class discussion. To check their symbolic thinking at each step, they used learning tools in addition and subtraction efficiently. According to Poynter (2004) and Tall (2007a), the abstraction process combined manipulation on physical objects and symbols to support students' mathematical thinking based on Poynter (2004) and Tall (2007a). For further study, the research will present the integration of embodiment and symbolic.

\section{Conclusion and Discussion}

Students' concept to solve problem based on Tall and Isoda (2007) in the fourth step of compression in action process of abstraction to thinkable concept. Thinkable concept interacts with thinking tools in action process of abstraction through compression important ideas into thinkable concept.

Considering students' thinking tools in steps 3, 4 and 5 from procedure to thinkable concept, the students recognized concept formation and this concept was built to utilize later.

Students used 10 as "how to" to build thinkable concept. They understood the value of "how to" which help them to extend the mathematics structure. Howat (2005) viewed that the students 


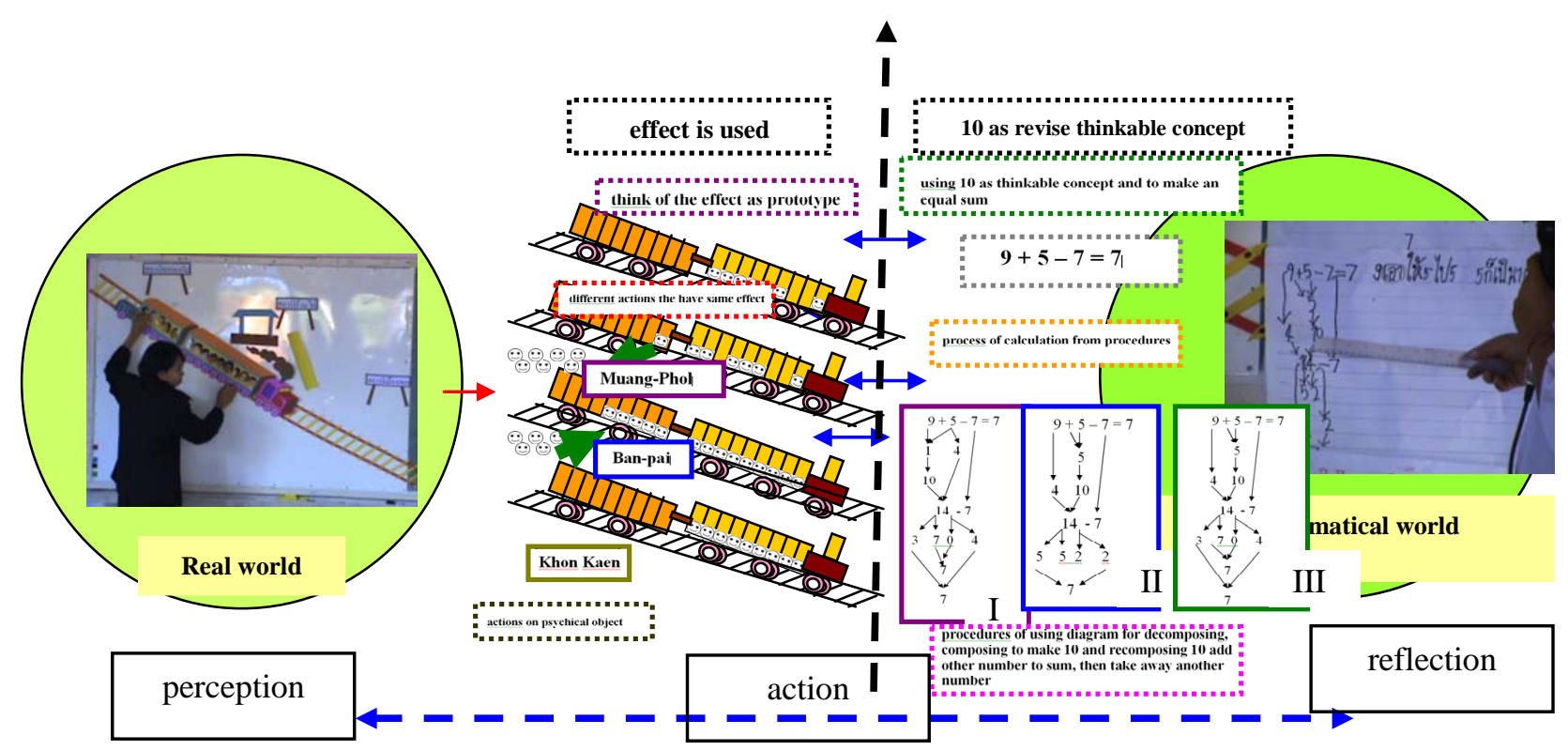

Figure7.

"how to" in the students' abstraction process through compression to thinkable concept under classroom using Lesson Study and Open Approach.

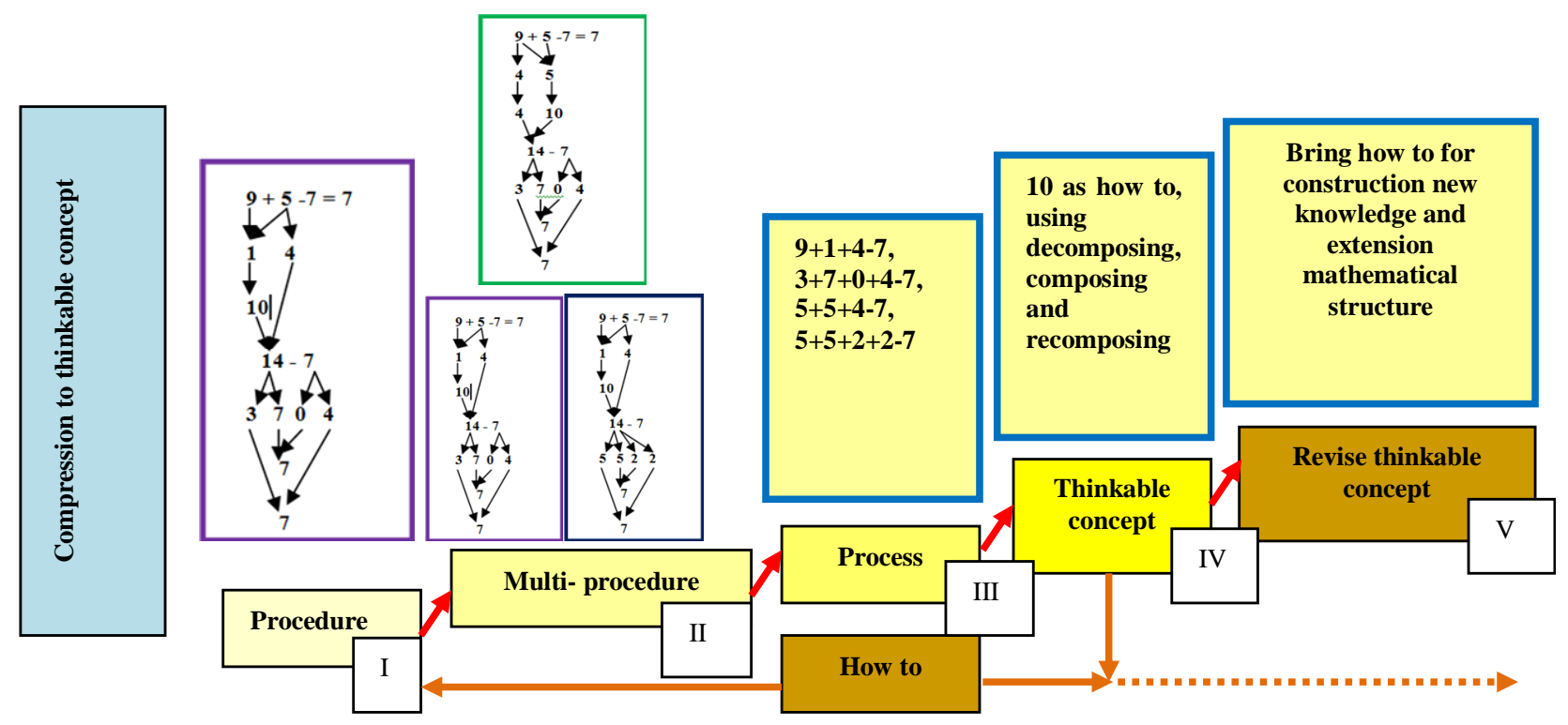

Figure 8.

"how to" in the students' abstraction process through compression to thinkable concept.

will not cope with place value if they cannot form the concept of "ten" as a thinkable concept. This study found that "how to" is important and it is a tool to build thinkable concept as following:

1) Students used "how to" and base 10 to decompose, compose and recompose for providing the part-part or part-whole.

2) "how to" makes extension mathematical structure on base 10 through addition and subtraction. Students used their previous (met-before) knowledge to construct new knowledge.

3) "how to" makes students to realize the different procedures to solve math's problem. Students used meaningful and efficient way to solve problem and they saw mathematical values.

In particular, "how to" is to be compared as a measure of success in students' solving problem and concepts formation.
They use it to achieve flexibility and effectiveness of problem solving effectively and quickly, whenever. To prepare using "how to" in learning units of lesson sequences is to provide a tool in conducting students' concepts.

The further study, the research will present the student's abstraction process through compression to thinkable concept focused on the student's thinking procedures in interacting with learning materials and symbolic calculation that is integrated between embodiment and symbolism according to Tall (2007a).

\section{Acknowledgements}

This work was supported by the Higher Education Research Promotion and National Research University Project of Thai- 
land, Office of the Higher Education Commission, through the Cluster of Research to Enhance the Quality of Basic Education and Center for Research in Mathematics Education, Faculty of Education, Khon Kaen University, Thailand.

\section{REFERENCES}

Biggs, J., \& Collis, K. (1982). Evaluating the quality of learning: The SOLO taxonomy. New York: Academic Press.

Davis, R. B. (1984). Learning mathematics: The cognitive science approach to mathematics education. Norwood, NJ: Ablex.

Dubinsky, E. (1991). Reflective abstraction in advanced mathematical thinking. In D. O. Tall (Ed.), Advanced mathematical thinking (pp. 95-123). Dorfrecht: Kluwer.

Howat, H. (2005). Participation in elementary mathematics: An analysis of engagement, attainment and intervention. Ph.D. Thesis, Warwick: University of Warwick.

Gakkotosho Co., Ltd. (2005). Study with your friends MATHEMATICS for elementary school 1st grade. Tokyo: Gakkotosho Co., LTD.

Gray, E., \& Tall, D. O. (1994). Duality, ambiguity and flexibility: A proceptual view of simple arithmetic. Journal for Research in Mathematics Education, 25, 115-141. doi:10.2307/749505

Gray, E., \& Tall, D. (2007). Abstraction as a natural process of mental compression. Mathematics Education Research Journal, 19, 23-40. doi:10.1007/BF03217454

Inprasitha, M. (1997). Problem solving: A basis to reform mathematics instruction. Reprinted from the Journal of the National Research Council of Thailand, 29, 221-259.

Inprasitha, M., Pattanajak, A., \& Thasarin, P. (2007). To prepare context for leading the teacher professional development of Japan to be called "Lesson Study" implemented in Thailand. Bangkok: Thammasat University, 152-163.

Inprasitha, M. (2010). One feature of adaptive lesson study in Thailand: Designing a learning unit. Proceedings of the 45th Korean National Meeting of Mathematics Education. Gyeongju: Dongkook University, 8-9 October 2010, 193-206.

Isoda, M. (2010). The principles for problem solving approach and open approach: As a product of lesson study. International Conference on Educational Research (ICER 2010), Learning Communities for Sustainable Development, 10-11 September 2011.

Leslie, P. S., \& Patrick, W. T. (2000). Teaching experiment methodology: Underlying principles and essential elements. Handbook of research design in mathematics and science education (pp. 267-306). Mahwah: Lawrence Erlbaum Associate.
Nohda, N. (1998). Mathematics teaching by "open-approach method" in Japanese classroom activities. Proceedings of ICMI-EARCOME 1, 17-21 August 1998, 185-192.

Nohda, N. (2000). Teaching by approach method in Japanese mathematics classroom. Proceeding of the 24th Conference of the International Group for the Psychology of Mathematics Education, 11-39.

Poynter, A. (2004). Effect as a pivot between actions and symbols: The case of vector. Ph.D. Thesis, Warwick: University of Warwick.

Pegg, J., \& Tall, D. O. (2005). The fundamental cycle of concept costruction underlying various theoretical framework. ZDM (Mathematics Education), 37, 468-475. doi:10.1007/BF02655855

Sfard, A. (1991). On the dual nature of mathematical conceptions: Reflections on processes and objects as different sides of the same coin. Educational Studies in Mathematics, 22, 1-36. doi:10.1007/BF00302715

Skemp, R. R. (1971). The psychology of learning mathematics. London: Pengin.

Skemp, R. R. (1987). The psychology of learning mathematics. London: Lawrence Erlbaum Associated, Inc., 9-21.

Suthisung, N. and Sangaroon, K. (2011a). The steps up of compression to thinkable concept inaction of the student's abstraction process. The 16th Annual Meeting in Mathematics (AMM 2011), 10-11 March 2011.

Suthisung, N., \& Sangaroon, K. (2011b). "How to” in the students' abstraction process through compression to thinkable concept. Proceedings of the 35th Conference of the International Group for the Psychology of Mathematics Education (Developing Mathematical Thinking). Ankara, 10-15 July 2011, 1-398.

Tall, D. O. (2004). The nature of mathematical growth. URL (last checked 23 March 2010).

http://www.tallfamily.co.uk/david/mathematical-growth

Tall. D. O. (2006). A theory of mathematical growth through embodiment, symbolism and proof. Annales de Didactique et de Sciences Cognitives, 1, 195-215.

Tall, D. O. (2007a). Developing a theory of mathematical growth. ZDM, 39, 145-154. doi:10.1007/s11858-006-0010-3

Tall, D. O. (2007b). Setting lesson study within a long-term framework of learning. APEC Conference on Lesson Study in Thailand, 1-17.

Tall, D. O. (2008). Using Japanese lesson study in teaching mathematics. Scottish Mathematical Council Journal, 38, 45-50.

Tall, D. O., \& Isoda, M. (2007). Long-term development of mathematical thinking and lesson study. Chapter for a Forthcoming Book on Lesson Study.

Tall, D. O, Thomas, M., Davis, G., \& Gray, E. (2000). What is the object of the encapsulation of a process? Journal of Mathematical Behavior, 18, 223-241. doi:10.1016/S0732-3123(99)00029-2 